\title{
Evaluation of Tear Film Osmolarity Among Diabetic Patients Using a TearLab Osmometer
}

\author{
Ali Abusharha \\ Ali Alsaqar (iD \\ Raied Fagehi (iD \\ Mohammad Alobaid \\ Ali Almayouf \\ Sulaiman Alajlan \\ Mossab Omair \\ Essa Alahmad \\ Ali Masmali
}

Department of Optometry, College of Applied Medical Sciences, King Saud University, Riyadh, I 1433, Saudi Arabia
Correspondence: Ali Abusharha Department of Optometry, College of Applied Medical Sciences, King Saud University, P.O. Box 10219, Riyadh, I 1433, Saudi Arabia

Email aabusharha@ksu.edu.sa
Purpose: The purpose of the present study is to determine the effects of type 2 diabetes mellitus on tear osmolarity using a TearLab Osmolarity system. Moreover, the relationship between tear film osmolarity and ocular surface discomfort in controlled and uncontrolled diabetic patients was assessed.

Materials and Methods: This study included 20 male type 2 diabetic patients aged 20 to 70 years (mean \pm SD $49 \pm 12$ ). A control group (18-43 years; $32.2 \pm 6.5$ years) consisting of 40 male subjects was also enrolled for comparison. The tear osmolarity was measured using the TearLab Osmolarity System. The ocular surface disease index questionnaire (OSDI) was used to assess ocular discomfort symptoms.

Results: The mean tear osmolarity was $297 \pm 8.00$ and $296 \pm 11 \mathrm{mOsm} / \mathrm{L}$ for controlled and uncontrolled diabetic subjects, respectively, while the average osmolarity in the control group was $299 \pm 8.00 \mathrm{mOsm} / \mathrm{L}$. No significant differences were detected in tear osmolarity between the control and diabetes groups. The ocular surface disease index questionnaire (OSDI) score was significantly higher in the diabetic patient group. No significant correlation was found between tear osmolarity and OSDI scores.

Conclusion: The ocular discomfort symptoms score in diabetic patients was significantly higher compared to normal eye subjects. Tear osmolarity was not significantly different in diabetic patients. This finding may be explained by a lack of relationship between tear film parameters and diabetic severity; tear film parameters may correlate more with diabetic duration rather than severity. Therefore, studies focused on diabetes duration and tear film parameters are recommended.

Keywords: diabetes, dry eye, tear film osmolarity

\section{Introduction}

Dry eye disease (DED) is a common ocular surface disease. DED is associated with increased tear osmolarity and mild to severe ocular surface irritability and inflammation. ${ }^{1}$ Normal tear tonicity is determined by the presence of cations (sodium, potassium, calcium, magnesium, iron, and copper) and anions (chlorides, bicarbonates, and phosphates). ${ }^{2}$ Sodium chloride is the most abundant cation present in tears. Other macromolecules, such as proteins and sugars, also contribute to tear tonicity. ${ }^{2}$ The tear film aqueous layer mainly contains glucose, electrolytes, antibodies, and antibacterial proteins. ${ }^{3}$

Hyperosmolarity of the tear film is the central mechanism leading to ocular surface abnormalities. ${ }^{4}$ It is accepted today that there is a relationship between tear hyperosmolarity and ocular surface inflammatory events. Thus, tear hyperosmolarity may eventually lead to ocular surface damage and dry eye symptoms, including 
ocular discomfort and redness. ${ }^{4}$ Farris suggested that tear film osmolarity be considered the new gold standard for the diagnosis of dry eye syndrome, due to the simplicity and reliability of tear osmolarity measurements. ${ }^{5}$

At present, there are numerous clinical tools used to diagnose dry eye symptoms. Methods, such as dry eye questionnaires, measuring tear quantity with paper strips, and ocular surface staining, have been widely used to diagnose dry eye syndrome. ${ }^{6,7}$ It has been demonstrated that tear osmolarity is the single best tool to diagnose and grade the severity of dry eye syndrome. $^{7}$ However, the tear osmolarity test has a major drawback; values of tear film osmolarity in normal and dry eye individuals overlap. Many cut off values for dry eye syndrome have been proposed. Cutoff values between 305 to $316 \mathrm{mOsm} / \mathrm{L}$ have been reported to differentiate between normal and dry eye patients. ${ }^{8}$

Recent reports show that the prevalence of diabetes in the Middle East and North Africa is $12.2 \%$. An estimated 4.3 million people living in Saudi Arabia were diagnosed with diabetes mellitus. ${ }^{9}$ Diabetes mellitus is one of the risk factors of dry eye syndrome. Lacrimal secretomotor function can be affected due to a reduction in corneal sensitivity that may result in a reduction in tear production. ${ }^{10}$ Corneal sensitivity controls the process of tear secretion. ${ }^{11}$ Poor tear production leads to hyperosmolarity which affects the ocular surface and causes ocular discomfort symptoms and inflammatory events. ${ }^{12}$ Autonomic neuropathy abnormalities found in diabetic patients could play an important role in reduced corneal sensitivity leading to poor lacrimation. ${ }^{11}$ Poor tear production leads to hyperosmolarity which affects the ocular surface and causes ocular discomfort symptoms and inflammatory events. ${ }^{13}$ In addition, corneal and conjunctival epithelial abnormalities are observed in diabetes mellitus patients. ${ }^{13}$ Moreover, ocular complications, such as retinopathy, corneal sensitivity defect, cataracts, and corneal lesions, are also associated with diabetes. ${ }^{14}$

The purpose of the present study was to determine the effects of type 2 diabetes mellitus on tear osmolarity using the TearLab Osmolarity System. We also investigated the extent to which diabetes mellitus alters tear film osmolarity. Moreover, the relationship between tear film osmolarity and ocular surface discomfort in controlled and uncontrolled diabetic patients was assessed.

\section{Materials and Methods}

\section{Subjects}

This study included 20 male type 2 diabetic patients, aged 20 to 70 years (mean \pm SD $49 \pm 12$ ). A control group (1843 years; $32.2 \pm 6.5$ years) consisting of 40 male subjects was also enrolled for comparison. Controlled and uncontrolled diabetes were diagnosed based on the hemoglobin A1c (HbA1c) test. An HbAlc level above $6.5 \%$ was defined as uncontrolled, while a level below $6.5 \%$ was considered controlled diabetes. The exclusion criteria included subjects who had any ocular diseases, surgery, continuous use of ocular medication, or contact lens use during the previous month. All study procedures were explained to the subjects and consent forms were signed by all subjects. Ethical approval was obtained from the College of Applied Medical Sciences Ethics Committee. The participants were treated according to the tenets of the Declaration of Helsinki.

\section{Dry Eye Questionnaire}

Subjects were asked to complete the ocular surface disease index (OSDI) questionnaire. The OSDI includes 12 questions on different ocular symptoms. A score of 12 was used as the cut off value between normal and dry eye patients.

\section{Tear Film Osmolarity}

The tear osmolarity was measured using the TearLab Osmolarity System (TearLab Corp., San Diego, CA, USA) Nano tear samples were collected from the inferior lateral meniscus using single-use disposable chips. Then, the handheld pen was placed in the stationary reader to analyze the sample and measure the tear sample osmolarity.

\section{Statistical Analysis}

The data were collected using Excel (Microsoft ${ }^{\mathrm{TM}}$ Office 2010, Microsoft Corp., Redmond, USA) and analyzed using the SPSS $^{\circledR}$ statistical package, version 22.0 (SPSS Inc., Chicago, IL, USA) for Windows ${ }^{\circledR}$. A test of normality was carried out first using a Kolmogorov-Smirnov test. Normally distributed data were compared using Independent Sample $t$ test. Data not normally distributed were compared using Mann-Whitney $U$-test.

\section{Result}

The average HbA1c of all diabetic patient subjects was 7.91 $\pm 2.89 \%$. Mean HbAlc was $5.86 \pm 0.93$ and $10.26 \pm 2.51 \%$ 
in controlled and uncontrolled diabetic subjects respectively. $\mathrm{HbA1c}$ in the uncontrolled group ranged from 7.2 and 14. Twenty-seven percent of subjects had an HbAlc between 7 and $10 \%$ and $22 \%$ of subjects had HbAlc above $10 \%$.

The mean tear osmolarity was $297 \pm 8.00$ and $296 \pm 11$ $\mathrm{mOsm} / \mathrm{L}$ for controlled and uncontrolled diabetic subjects, respectively (Figure 1). The average osmolarity reading in the control group was $299 \pm 8.00 \mathrm{mOsm} / \mathrm{L}$. The tear osmolarity reading ranged from 288 to $310 \mathrm{mOsm} / \mathrm{L}$ and 285 to
$320 \mathrm{mOsm} / \mathrm{L}$ in the control and diabetic groups, respectively. Parametric testing showed no significant differences in tear osmolarity between normal subjects and diabetic patients.

The ocular surface disease index questionnaire (OSDI) scores were significantly higher among diabetic patients compared with individuals in the control group. The mean OSDI score was $4.75 \pm 3.27$ and $11.75 \pm 5.98$ in the control and diabetic groups, respectively (Figure 2). The mean OSDI score for uncontrolled diabetic patients $(13.4$

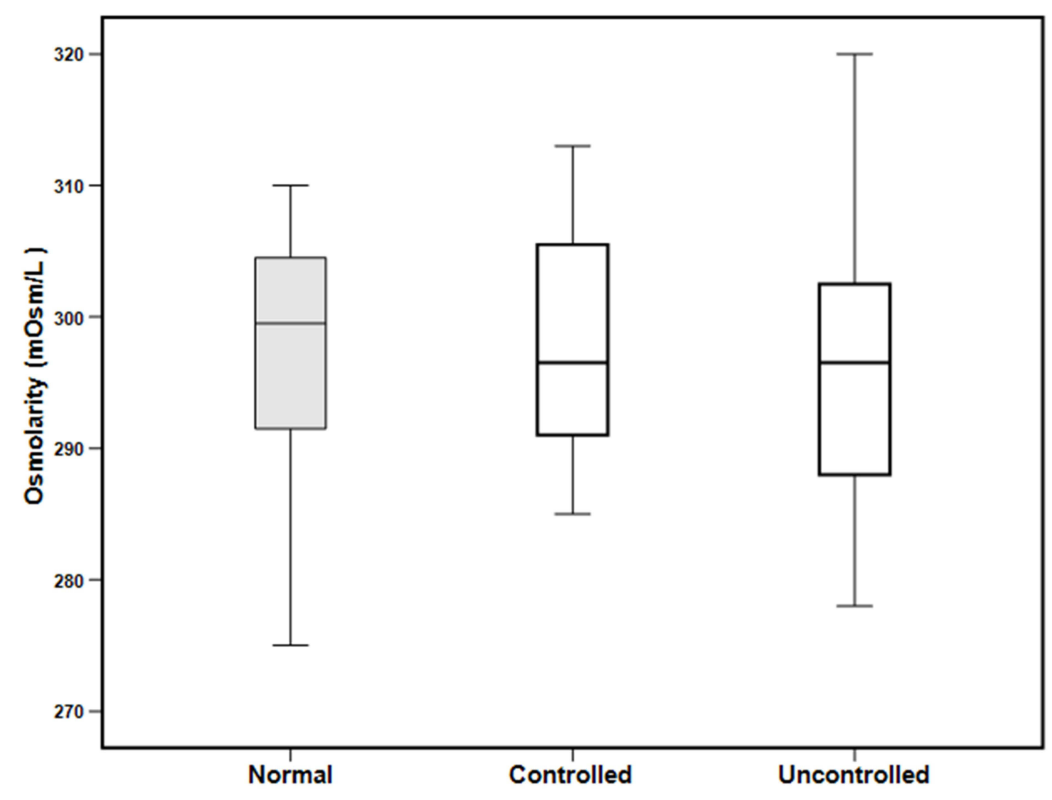

Figure I A box plot showing tear osmolarity measured in normal subjects and subjects with controlled and uncontrolled diabetes. No significant differences were found.

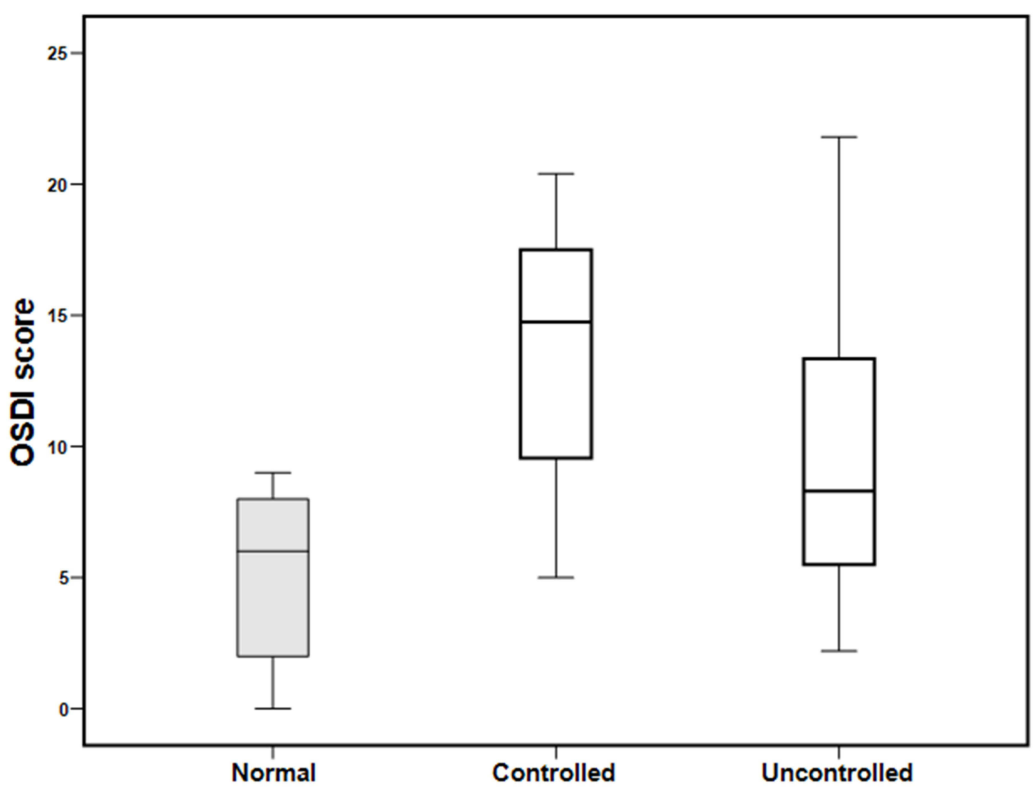

Figure $2 \mathrm{~A}$ box plot showing tear ocular surface disease index score measured in normal subjects and subjects with controlled and uncontrolled diabetes. Significantly increased ocular discomfort symptoms were observed in controlled and uncontrolled diabetic patients compared with normal subjects. 
\pm 4.96) was higher compared with the controlled diabetic subjects $(9.74 \pm 6.11)$; however, the difference was not statistically significant. The correlation test was applied to assess the relationship between tear film osmolarity and OSDI scores and no significant correlation was found $(\mathrm{r}=$ $0.3 ; \mathrm{P}=0.06$ ).

\section{Discussion}

This study describes the effect of diabetes mellitus on tear film osmolarity, measured using the TearLab Osmolarity System. Tear film osmolarities in controlled and uncontrolled diabetic patients were compared. The mean $\mathrm{HbA} 1 \mathrm{c}$ in diabetic patients was $7.91 \pm 2.89 \%$. The tear osmolarity reading ranged from 285 to $320 \mathrm{mOsm} / \mathrm{L}$ among subjects with diabetes with an average value of $296 \pm 11 \mathrm{mOsm} / \mathrm{L}$. These results match those observed in an earlier study. ${ }^{15}$ Najafi et al showed that tear osmolarity was $301 \mathrm{mOsm} / \mathrm{L}$ in patients with diabetes mellitus. However, higher osmolarity measurements were reported among diabetic patients in another report. ${ }^{15}$ Fuerst et al reported that the average tear osmolarities were 311 and $302 \mathrm{mOsm} / \mathrm{L}$ in male and female diabetic patients, respectively. ${ }^{16}$ The values reported by Fuerst et al for tear osmolarity in female diabetic patients $(302 \mathrm{mOsm} / \mathrm{L})$ were similar to the values determined in our study. ${ }^{16}$ However, the same study reported higher osmolarity values among male patients. ${ }^{16}$

In the current study, no significant differences were observed in tear osmolarity between controlled and uncontrolled diabetic patients and no correlation was found between $\mathrm{HbA} 1 \mathrm{c}$ and tear osmolarity measurements. This result is in agreement with previous reports showing no correlation between $\mathrm{HbA} 1 \mathrm{c}$ levels and tear film osmolarity, although tear osmolarity was significantly higher among diabetic patients. ${ }^{17}$ However, the same study demonstrated a significant correlation between tear osmolarity and the duration of diabetes mellitus. ${ }^{17}$ Another study by Derakhshan et al showed no significant difference in the tear film osmolarity between patients with diabetes mellitus and normal individuals. ${ }^{18}$ The discrepancy in these reports may be due to the complexity of lacrimal function and the multifactorial nature of dry eye symptoms.

In this study, we found that the OSDI score was significantly higher among diabetic patients compared with the control group; the OSDI score in diabetic subjects was threefold higher than that observed in the control group. Excessive use of lubricant eye drops has been reported among patients with higher HbAlc. ${ }^{19}$ Furthermore, more than $50 \%$ of diabetic subjects have dry eye symptoms. ${ }^{9}$
These reports are consistent with the results of our study, indicating that patients with diabetes mellitus have greater ocular discomfort.

The major factor responsible for dry eye in diabetes mellitus is increased glycemic levels, which leads to corneal neuropathy. ${ }^{20}$ Associations between poor corneal sensation, decreased tear secretion, and uncontrolled diabetes mellitus are well documented. ${ }^{21}$ Also, diabetic patients have increased keratoepitheliopathy scores compared with normal subjects. Moreover, conjunctival squamous metaplasia and decreased goblet cell density have been reported in uncontrolled diabetic patients. ${ }^{22}$ Therefore, ocular surface damage and tear film instability may play a vital role in promoting the symptoms of ocular discomfort.

No statistically significant correlation was observed between tear osmolarity and OSDI scores in our study. In contrast, a previous study showed a positive relationship between tear film osmolarity and ocular discomfort symptoms. These discrepancies may have developed because tear film parameters are more closely associated with the duration of diabetes rather than the severity of diabetes mellitus. ${ }^{18}$ There are still many unanswered questions about the relationship between tear osmolarity and the duration of diabetes mellitus.

\section{Conclusion}

The ocular discomfort symptoms score in diabetic patients was significantly higher compared to those obtained from the eyes of normal subjects. Tear osmolarity showed no significant changes in diabetic patients. Alterations in tear film parameters in diabetes mellitus may be associated more with the duration rather than the severity of diabetes mellitus. More research is needed, focusing on this relationship. Moreover, since the study was aimed to investigate tear osmolarity in type 2 subjects, it was not possible to enrolled younger subjects for the purpose of age matched with the control group. Therefore, further work needs to be done to establish whether these results can be repeated in younger patients with type 2 diabetes.

\section{Abbreviations}

DED, Dry eye disease; OSDI, ocular surface disease index.

\section{Ethics Statement}

All study procedures were explained to the subjects and consent forms were signed by all subjects. Ethical 
approval was obtained from the College of Applied Medical Sciences Ethics Committee. The participants were treated according to the tenets of the Declaration of Helsinki.

\section{Acknowledgments}

The authors extend their appreciation to the College of Applied Medical Sciences Research Center and the Deanship of Scientific Research at King Saud University for funding this research.

\section{Disclosure}

The authors report no conflicts of interest in this work.

\section{References}

1. Willcox MDP, Argüeso P, Georgiev GA, et al. TFOS DEWS II tear film report. Ocul Surf. 2017;15:366-403.

2. Murube J. Tear osmolarity. Ocul Surf. 2006;4:62-73. doi:10.1016/ S1542-0124(12)70028-9

3. Albietz JM. Dry eye: an update on clinical diagnosis, management and promising new treatments. Clin Exp Optom. 2001;84:4-18. doi:10.1111/j.1444-0938.2001.tb04930.x

4. Craig JP, Nichols KK, Akpek EK, et al. TFOS DEWS II definition and classification report. Ocul Surf. 2017;15:276-283. doi:10.1016/j. jtos.2017.05.008

5. Farris RL. Tear osmolarity - a new gold standard? Adv Exp Med Biol. 1994;350:495-503.

6. Bron AJ. Methodologies to diagnose and monitor dry eye disease: report of the Diagnostic Methodology Subcommittee of the international Dry Eye WorkShop (2007). Ocul Surf. 2007;5:108-152.

7. Lemp MA, Bron AJ, Baudouin C, et al. Tear osmolarity in the diagnosis and management of dry eye disease. Am J Ophthalmol. 2011;151:792-798.e1. doi:10.1016/j.ajo.2010.10.032

8. Tomlinson A, Doane MG, McFadyen A. Inputs and outputs of the lacrimal system: review of production and evaporative loss. Ocul Surf. 2009;7:186-198. doi:10.1016/S1542-0124(12)70186-6

9. Manaviat MR, Rashidi M, Afkhami-Ardekani M, Shoja MR. Prevalence of dry eye syndrome and diabetic retinopathy in type 2 diabetic patients. BMC Ophthalmol. 2008;8:10. doi:10.1186/14712415-8-10
10. Kan S, Acar U, Kizilgul M, et al. The effects of blood glucose regulation on tear function tests in diabetic patients. $J \mathrm{Fr}$ Ophtalmol. 2017;40:499-504. doi:10.1016/j.jfo.2016.10.019

11. Lyu Y, Zeng X, Li F, Zhao S. The effect of the duration of diabetes on dry eye and corneal nerves. Contact Lens Anterior Eye. 2019;42:380-385. doi:10.1016/j.clae.2019.02.011

12. Baig MA, Munir R. Dry eye disease and diabetes mellitis. Pak J Ophthalmol. 2020;36. doi:10.36351/pjo.v36i3.1003

13. Azar DT, Spurr-Michaud SJ, Tisdale AS, Gipson IK. Altered epithelial-basement membrane interactions in diabetic corneas. Arch Ophthalmol. 1992;110:537-540. doi:10.1001/ archopht.1992.01080160115045

14. Alves Mde C, Carvalheira JB, Módulo CM, Rocha EM. Tear film and ocular surface changes in diabetes mellitus. Arq Bras Oftalmol. 2008;71(6):96-103. doi:10.1590/S0004-27492008000700018

15. Najafi L, Malek M, Valojerdi AE, et al. Dry eye and its correlation to diabetes microvascular complications in people with type 2 diabetes mellitus. J Diabetes Complications. 2013;27:459-462. doi:10.1016/j. jdiacomp.2013.04.006

16. Fuerst N, Langelier N, Massaro-Giordano M, et al. Tear osmolarity and dry eye symptoms in diabetics. Clin Ophthalmol. 2014;8:507-515.

17. Sağdık HM, Ugurbas SH, Can M, et al. Tear film osmolarity in patients with diabetes mellitus. Ophthalmic Res. 2013;50:1-5. doi: $10.1159 / 000345770$

18. Derakhshan A, Abrishami M, Khajedaluee M, Omidtabrizi A, Moghaddam SG. Comparison between tear film osmolar cocentration and other tear film function parameters in patients with diabetes mellitus. Korean J Ophthalmol. 2019;33:326-332. doi:10.3341/ kjo.2013.0146

19. Kaiserman I, Kaiserman N, Nakar S, Vinker S. Dry eye in diabetic patients. Am $J$ Ophthalmol. 2005;139:498-503. doi:10.1016/j. ajo.2004.10.022

20. Bikbova G, Oshitari T, Baba T, Bikbov M, Yamamoto S. Diabetic corneal neuropathy: clinical perspectives. Clin Ophthalmol. 2018;12:981-987. doi:10.2147/OPTH.S145266

21. Cousen P, Cackett P, Bennett H, Swa K, Dhillon B. Tear production and corneal sensitivity in diabetes. $J$ Diabetes Complications. 2007;21:371-373. doi:10.1016/j.jdiacomp.2006.05.008

22. Yoon KC, Im SK, Seo MS. Changes of tear film and ocular surface in diabetes mellitus. Korean $J$ Ophthalmol. 2004;18:168-174. doi:10.3341/kjo.2004.18.2.168
Clinical Optometry

\section{Publish your work in this journal}

Clinical Optometry is an international, peer-reviewed, open access journal publishing original research, basic science, clinical and epidemiological studies, reviews and evaluations on clinical optometry. All aspects of patient care are addressed within the journal as well as the practice of optometry including economic and business analyses. Basic and clinical research papers are published that cover

Submit your manuscript here: https://www.dovepress.com/clinical-optometry-journal all aspects of optics, refraction and its application to the theory and practice of optometry. The manuscript management system is completely online and includes a very quick and fair peer-review system, which is all easy to use. Visit http://www.dovepress.com/ testimonials.php to read real quotes from published authors. 